\title{
Çeviri Yazı, Romanizasyon ve Kütüphanecilik
}

\author{
Transliteration, Romanization and Librarianship
}

\author{
Elif İbşiroğlu Bayram*
}

$\ddot{O} z$

Amaç: Bir dilin alfabesinde yer alan harflerin başka bir dilin alfabesine dönüştürülmesi, bir eserin ya da metnin başka bir dile aktarılması çeviri sistemleri ile sağlanmaktadır. Bu çalışmada, çeviri sırasında karşılaşılan sorunlara değinmek amaçlanmıştır. Yöntem: Harflerin dönüşümü, metinlerin aktarımı sırasında meydana gelen sorunlar günümüzün tartışma konusu olmuştur. Konunun değerlendirilmesi, anahtar sözcükler yardımıyla yerli ve yabancı literatür taranarak yapılmış ve elektronik kaynaklardan faydalanılmıştır. Bulgular: Bu çalışmada çeviri yazı ve romanizasyon kavramları ile birlikte dönüşüm, aktarım sırasında karşılaşılan sorunlara değinilmiştir. Disiplinler arası alanda ve kütüphanecilik alanında yapılan çalışmalar bu konuda sorunların olduğunu göstermiştir. Sonuç: Kavramlar kütüphanecilik açısından ele alınmış, bu alanda yaşanan sorunlar kataloglama ve kullanıcı özelinde değerlendirilmiştir. Özgünlük: Konu ile ilgili farklı alanlarda ve kütüphanecilik alanında çalışmalar yapılmıştır. Bu çalışma ile konuya kütüphanecilik açısından ışık tutulmaya çalışılmıştır.

Anahtar Sözcükler: Çeviri yazı; kataloglama; kütüphanecilik; romanizasyon.

\begin{abstract}
Objective: The conversion of the alphabet letters of a language to another alphabet letters and the transfer of a work or text to another language are achieved by translation systems. In this study, it is aimed to address the problems encountered during translation. Method: The issue of transformation of letters and problems that occur during the transfer of texts have been today's matters of debate. The research topic was evaluated with the help of related keywords scanned from domestic and international literature, and electronic resources were used. Findings: In this study, along with the concepts of transliteration and romanization, the problems encountered during transformation and transfer are discussed. Studies in the interdisciplinary field and in the field of librarianship have shown that there are problems in this regard. Implications: Concepts are dealt with in terms of librarianship and the problems experienced in this field are evaluated in terms of cataloging and user. Originality: Studies have been carried out in different fields related to the subject and in the field of librarianship. With this study, it was tried to shed light on the subject in terms of librarianship.
\end{abstract}

Keywords: Transliteration; cataloging; librarianship; romanization.

\footnotetext{
${ }^{*}$ Bursa Uludağ Üniversitesi Kütüphane ve Dokümantasyon Daire Başkanlığı, Bursa, Türkiye. E-posta: ielif@uludag.edu.tr

Bursa Uludağ University Library, Bursa,Turkey.E-mail: ielif@uludag.edu.tr
}

Geliş Tarihi - Received: 17.04.2021

Kabul Tarihi - Accepted: 29.04.2021

Yayımlanma Tarihi - Published: 30.06 .2021 


\section{Giriş}

Bir dilin alfabesinde yer alan tüm seslerin özel harflerle başka dilin alfabesine aktarılması (Uzun, 2020, s. 247) anlamına gelen ve transkripsiyon olarak da ifade edilen çeviri yazı, uygulandığı dile uygunluğu açısından gerek Türkçe gerek diğer diller için günümüzün tartışılan bir konusudur. Geçmişten gelen metinlerin aktarımında farklılıklar görülmektedir. Eski ve yeni Türkçe metinlerde alfabeler farklı olduğundan, çeviri yazı yöntemi ile aktarım zorlaşmakta; bu durum dili anlaşılmaz kılmaktadır (Çetin Milci, 2015, s. 165). Yazı, geçmişten günümüze farklı kültürlerin dil yoluyla aktarılmasını sağlamaktadır. Metni aktarırken dili doğru kullanmak, edinilen bilginin doğruluğunu da etkilemektedir.

Belirli bir ağız yapısından yola çıkan yazı dilleri, çeşitli siyasal, sosyo-kültürel ve teknolojik gelişmelerin etkileşimi ile standart bir yapıya kavuşmaktadır. Türkiye Türkçesinin şekillenmesi Oğuzca ile başlamakta ve on üçüncü yüzyıldan günümüze kadar olan bir zaman dilimini kapsamaktadır. Türkçenin yazıya aktarımında Latin alfabesi temel ölçüt olmuştur (Korkmaz, 2011, s. 46). Türk edebiyatında on beşinci yüzyıl itibari ile şairler, mahlas (takma ad) kullanmaya başlamış; mahlasların özelliği Arapça ve Farsça sözcüklerden seçilmesi olmuştur. Çoğunluğunda Fuzûlî, Rûhî, Hayâlî örneklerinde olduğu gibi bağl1lık ve aidiyet bildiren ekler vardır. Ancak eki -iy imlâsı yerine -î- şeklinde yazmak, metinlerin çeviri yazısında (transkripsiyonunda) hatalara neden olmaktadır (Tokatl1, 2013, s. 203). Bir dilin ortaya çıkması ve zamanla gelişip şekillenmesi uzun bir süreç sonucunda olmaktadır. $\mathrm{Bu}$ anlamda Türk dili de oldukça eski bir tarihe sahiptir. Ancak zaman içerisinde farklı dillerle olan etkileşim çeviri hatalarını da beraberinde getirmiştir.

1990’lı yıllarda Sovyetler Birliği dağıldıktan sonra Türkiye'de Türk lehçelerinin aktarımında artış olmuş; aktarımlar sırasında karşılaşılan sorunlar bu konudaki çalışmaları hızlandırmıştır. Siyasal değişimlerin kültürel gelişmeleri etkilediği söylenebilir. Bir metnin/eserin aktarımında yazım ve imlâ kuralları o metnin/eserin doğru anlaşılmasında büyük öneme sahiptir. Bu noktada kaynak eser yerine aktarım yapılan dildeki yazım ve imlâ kurallarının dikkate alınması gerekmektedir (Yavuz, 2018, s. 216). Aktarım yapılırken, hedef dilin kurallarının iyi analiz edilmesi eserin doğru anlaşılmasını sağlayacaktır.

Türkiye'de çeviri yazı konusunun gündeme gelmesi, Türk alfabesinin Arap kökenli metinlerden Latin kökenli metinlere aktarılmaya başlanması ile olmuştur. Bu durum batılı bilim insanları için öncelikli bir çalışma alanı sağlamıştır (Ünver, 1993, s. 51). Son zamanlarda çeviri çalışmalarının yoğunlaştığı alanlardan biri Kore ile ilgilidir. Edebiyat dışında kültür, sanat ve tarih konularında yapılan çeviriler artmaktadır. Korece eserlerin özellikle yemek adları, bayram ve benzeri geleneğe dayalı çeviri yazılarının yanlışlığa sebebiyet vermemesi açısından Türkçe telaffuzlarına göre yapılması önem arz etmektedir (Türközü ve Ölçer, 2019, ss. 12-17). Arap kültürünün Türkiye üzerindeki etkisi, metinlerin aktarımı konusunda yaşanırken bu durum aynı zamanda çeviri yazının da tanınmasını sağlamıştır. Türkçenin günümüzde etkileşimde olduğu dillerden birinin Korece olduğu görülmektedir. Koreceden Türkçeye birçok alanda eserin çevirisinin yapıldığını söylemek mümkündür.

Farklı bir dildeki harfleri Latin alfabesine dönüştürmek için transliterasyon (harf çevirisi) sistemleri kullanılmakta; bu sürece de romanizasyon adı verilmektedir (Gul, 2018, ss. 1-2). Tablo 1'de Kongre Kütüphanesindeki tablolardan derlenen romanizasyon örneği görülmektedir. Buna göre Rusça ve Yunancada kullanılan bazı harfler seçilmiş; ana dilde ve 
romanizasyondaki karşılıkları büyük ve küçük harf kullanımları ile birlikte tabloda gösterilmiştir. Ana dilde özel işaretlerle kullanılan harflerin romanizasyon dönüşümlerindeki Latin harfli karşılıklarını tabloda görmek mümkündür.

Tablo 1

Rusça ve Yunanca romanizasyon tablosu

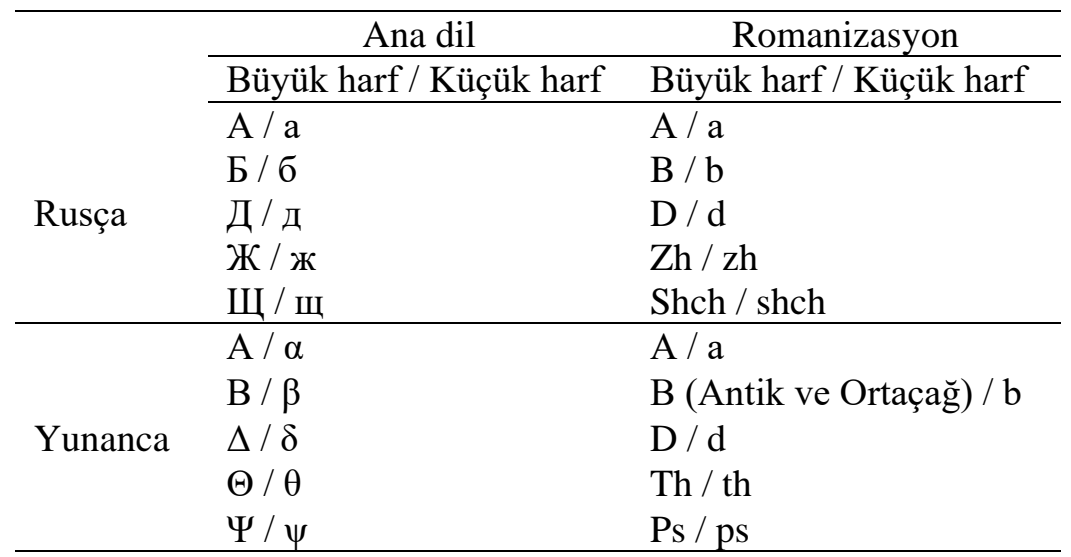

Not: (Romanization Tables, 2021)

Farklı yazı sistemlerindeki bir yazının Latin harflerine dönüştürülmesi zor bir süreçtir çünkü özgün dilin fonetiğine bağlı kalınması gerekmektedir. Latin kökenli olan dillerin dışındaki birçok dil İngilizcedeki karakterlerden farklı olarak kendine özgü çok sayıda ses içermektedir. Bu durum Batı Avrupa dışındaki dillerin ses ve harflerini Latin alfabesi ile ifade etmeyi zorlaştırmaktadır (Lawson, 2010, s. 164). Özel işaret ve sembollerden oluşan harflerin Latin harflerine dönüşümünün zor bir süreç olduğu anlaşılmaktadır. Aktarımda ana dilin özelliklerini yitirmemesi dikkat edilmesi gereken bir husus olarak işaret edilmektedir.

Transliterasyon (harf çevirisi), genellikle hem tüm diller için hem de yalnızca Latin alfabesini içeren diller için kullanılmakta; romanizasyon ise daha özel bir kullanıma sahip olmaktadır (Wang, 2000, s. 52).

\section{Kütüphanecilik Açısından Değerlendirme}

Kütüphaneler farklı koleksiyonların devamı için çok sayıda yabancı alfabelerde materyal toplamaktadır. Çoğu katalog ve bibliyografyada tek erişim aracı Roma alfabesi olduğundan katalogcuların bunları nasıl okuyacaklarını, çözümleyeceklerini bilmemeleri bir sorun olmaktadır (Weinberg, 1974, s. 20). Zengin koleksiyona sahip kütüphanelerde farklı dillerde yazılmış çok sayıda esere rastlamak mümkündür. Ancak bu eserlerin çözümlenmesi uzmanlık gerektirdiğinden bu durum sorun oluşturabilmektedir.

Yazar isimlerinin ve başlıklarının çevrilmesi ve kataloğa entegre edilmesi bir başka sorun olarak ifade edilebilir. "f” ve "ph” harflerinin birleştirilmesi, “ä”nın "ae” olarak yazılması transkripsiyon sürecinde bir bilgi kaybı yaratmaktadır. Bir kütüphaneye gelen süreli yayınlarda yabancı dizilerin her sayısı için profesyonel bir romanizasyon yapılması gerekmektedir. Aksi takdirde kendi transkripsiyonuyla geldikleri için mevcut kütüphane sistemine uymayacaktır. Uygun bir başlık girişi yapılmadığı durumda kullanıcının aradığı kaynağa erişmesi mümkün olmayacaktır (Weinberg, 1974, ss. 21-22). Çeviri yazıda harflerin özgün şekli ile aktarımı doğru bilgi açısından önem arz etmektedir. Aynı şekilde romanizasyondaki dönüşümün doğru yapılması kullanıcıların aradıkları bilgiye ve kaynağa daha kolay ulaşmasını sağlayacaktır. 
Arapça materyaller bibliyografik unsurların özellikleri bakımından farklı olabilmekte ve bu durum Arapça materyallerin tanımlanmasına ilişkin bazı sorunlar ortaya çıkarmaktadır. Arapça kitaplarda bulunmayan özellikler Arap harfli bu materyallerin kataloglanmasında sorun oluşturmaktadır. Arapça isimler bu sorunlardan biridir. Yayın tarihinin olmaması, baskı bilgilerinin doğrulanmasının zaman alması, değiş̧en kurum isimlerini tanımlayan ve doğrulayan kapsamlı ve tek bir listenin olmaması, Arapça materyallerin konu kataloglamaları için gerekli uluslararası sınıflama sistemleri ve konu başlıkları listelerindeki eksiklikler sorun olmaktadır (Khurshid, 2002, ss. 67-73).

Farsça materyallerin kataloglanması konusunda karşılaşılan sorunlardan birinin; ALALC romanizasyon tablolarının uygulanmasından kaynaklandığı görülmektedir. Amerikan kütüphanelerindeki kataloglama uygulamaları, basılı olan ve basılı olmayan Farsça materyallere kullanıcıların kolayca erişebilmesi için doğruluk ve basitlik açısından yeterli olmamaktadır. Kullanıcıların Farsça yayın ve basılı olmayan materyallerin doğru bibliyografik bilgilerine erişmelerini engelleyen sorunlar olmuştur. Bu sorun ve eksiklikler üç ana grupta toplanabilir. İlk gruptaki sorun, yeterli bir harf çeviri şemasının uygulanmamasından kaynaklanmaktadır. Farsça kelime ve isimlerin Latin harflerine dönüştürülmesi önemli bir tartışma konusudur. İkinci gruptaki sorun, Farsça bilgisinin eksikliğinden olmaktadır. Farsça kısa ünlülerin ( $\mathrm{a}$, e ve o) Arap alfabesinde görünmemesi, Farsça bilgisi olmayan bir katalogcunun yetkili bir kaynağa başvurmasını gerekli kılmaktadır. Üçüncü gruptaki sorun, Farsça isimlere Arapça kuralların uygulanmasıdır. Örneğin, Hoseyn gibi yaygın Farsça bir isim, Arapça kökenli (Hüseyin gibi) olduğu için çevirisi de Arapça şeklindedir. Farsça hakkındaki işlevsel bilgi eksikliği, ad otorite kayıtlarının oluşturulmasında ya da bibliyografik kayıtlardaki Farsça isimlerin transliterasyonunda sorunlara neden olmaktadır (Molavi, 2006, ss. 78-80). Farsça karakterlerin romanizasyon tablolarındaki dönüşümlerinin yeterli olmaması bu materyallerin çevirisinde bir problem oluşturmaktadır. Farsça ile ilgili bilgi eksikliği ve Farsça isimlere uygulanan kuralların Arapçadaki ile aynı olması Farsça çeviride karşılaşılan diğer sorunlar olmaktadır.

MARC (Machine Readable Cataloging Record - Makinece Okunabilir Kataloglama Kaydı) alanlarında özel karakterlerin kullanımına ilişkin karşılaşılan bazı sorunlara örnek olarak; çeviri bir kitabın 500 "Genel notlar” alanı için “Özgün eser adı” yazımı verilebilir. Rusçadan çevirisi yapılan "Bir Delinin Hatıra Defteri” adlı kitabın orijinal adı Kiril alfabesi ile “Записки сумасшедшего” şeklinde yazılmışsa; bu başlığın ilgili alanda aşağıdaki gibi gösterilmesi gerekecektir:

500--_aÖzgün eser ad1: Записки сумасшедшего.

Ancak bu karakterleri karşılayan bir uygulamanın olmaması bu harflerin yazımında katalogcu açısından bir sorun olacaktır.

Bir başka MARC alanı olan eser adı yazımında benzer bir sorunla karşılaşmak mümkündür. Örneğin, birden fazla dilde yazılmış bir kitabın (başlık) dillerinden birinin aşağıdaki gibi;

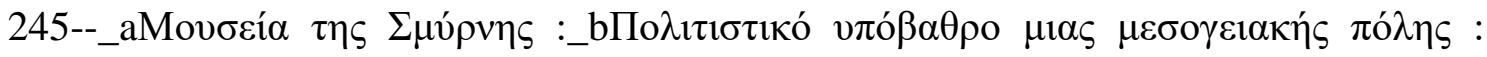

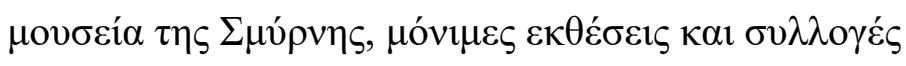


Yunanca olduğu bir durumda karakterlerin yazımı katalogcu açısından zorlayıcı ve bu eseri aramak isteyen kullanıcı açısından da bir problem olacaktır. Kullanımı kataloglama açısından farklı problemlere yol açan Yunanca teta $(\theta)$ karakterine, OCLC kataloglamasında Latin harfli alanlarda izin verilmemekte ve genellikle harfin adı köşeli parantez içinde [theta] şeklinde gösterilmekte ya da fonetik eşdeğeri ile değiştirilmektedir (Husic, 2011, ss. 42-43).

Yazar adı yazımında da karakter kullanımına ilişkin farklı uygulamalar olabilmektedir. Örneğin Danimarkalı filozof Søren Kierkegaard'ın adının 100 alanındaki kullanımları;

100--_aKierkegaard, Soren

100--_aKierkegaard, Sören

100--_aKierkegaard, Søren

gibi farklı şekillerde görülebilmektedir. Bu durum katalog kayıtlarında standart bir kullanım olmasını da zorlaştıracaktır.

Doğu Asya dil materyallerinin kataloglanmasında, Latin harflerine dönüşüm oldukça karmaşık bir konudur. Bu materyallerin, Romanizasyon şemaları ile Batı kataloglama sistemlerinde tanımlanması ve kullanıcıların Latin alfabesinde yazılmış arama terimlerini kullanarak söz konusu materyallere erişimi mümkündür. Romanizasyon, katalogcuların yalnızca Latin alfabesini destekleyen sistemlerde, Latin alfabesinde yazılmamış materyallerin bibliyografik kayıtlarının oluşturulmasına olanak tanımaktadır. Ayrıca, kullanıcıların Latin alfabesi dışında yazılmış bilgilere erişimini sağlamaktadır. Ancak, LC tarafından benimsenen ve kütüphanelerde kullanılan Korece için Latin harflerine dönüştürme şemasının, kullanıcıların bilgi arama ya da bilgi edinme becerilerini arttırmaları açısından etkili bir araç olduğu konusunda netlik yoktur (Kim, 2006, ss. 56-57). Romanizasyon, Latin harfleri dişında yazılmış eserlerin Latin alfabesine dönüştürülmüş biçimlerine erişmeyi olanaklı kılmaktadır. Ancak bazı romanizasyon şemalarının (örneğin Korece) kullanıcıların aradıkları bilgiye erişiminde etkili olduğu söylenemez.

Dünyanın farklı yerlerinde farklı yazı sistemleri vardır. Bu yazı sistemlerinde yer alan isimlere ve farklı sözcük ögelerine erişme ihtiyacı tarama yaparken transliterasyon açısından problem olabilmektedir. Alfabe açısından batıda Latin, doğuda Kiril, güneyde ise bölünmüş bir yapılanma söz konusudur. Ayrıca Latin ve demografik üstünlüğü bulunan Kiril alfabesi Slav grubunda bir arada yer almaktadır. Diğer alfabeler, özellikle Arapça, Gürcüce ve Ermenice, Osmanlı ve Sovyet gibi Slavca konuşan nüfusun olduğu eski devletlerde belirgindi. Slavlara yakın diğer ülkeleri Çin, Hindistan, Kore ve Japonya temsil etmekteydi. OCLC açısından, bu karmaşık transliterasyon matrisinde tek ortak nokta romanizasyon olmaktadır (Chroust, 2001, ss. 46-47). Dünya üzerinde farklı toplulukların bulunması birbirinden farklı alfabe ve yazı sistemlerinin gelişmesini sağlamıştır. Bu farklı sistemleri birleştiren unsur ise Latin harfleridir. 


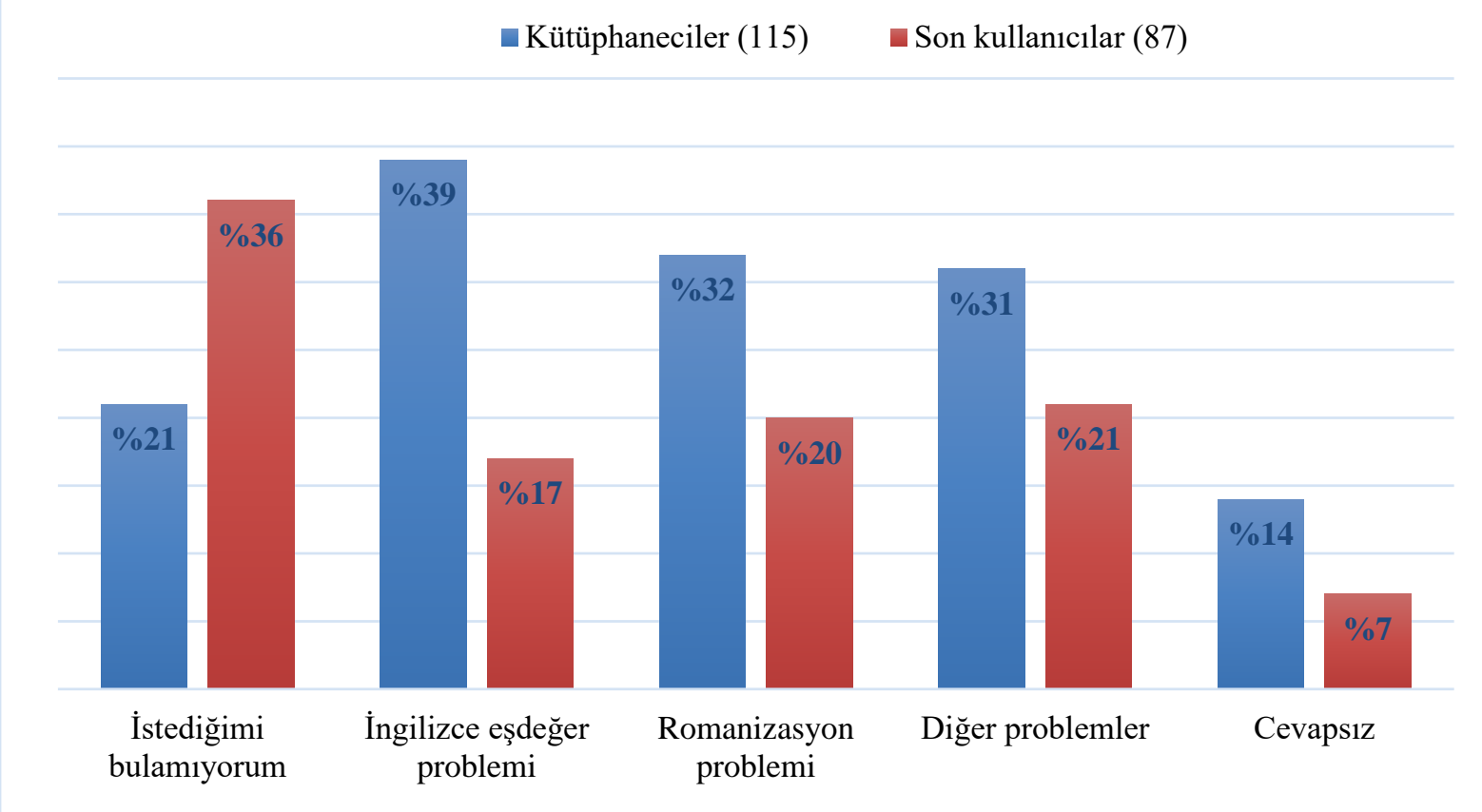

Şekil 1. İngilizce konu başlıklarını kullanarak Latince olmayan materyallere erişimde karşılaşılan sorunlar (El-Sherbini ve Chen, 2011, s. 467)

Kütüphaneci ve son kullanıcıların arama davranışlarının incelendiği Şekil 1'deki çalışma, araştırmaya 1 ş1k tutan ve konuyu destekleyen uygulamalardan birini göstermektedir. $\mathrm{Bu}$ çalışmaya göre; çoğu kütüphaneci konu araştırması yaparken İngilizce ya da Latin alfabesiyle yazılmış terimler kullanmaktadır. "İngilizce eşdeğer problemi” yaşadığını belirten kütüphaneci oranı kullanıcı oranından fazladır (\%39). Araştırmaya katılanların küçük bir yüzdesi, bu materyalleri aramak için hem İngilizce hem de orijinal metinleri kullanmaktadır. Konu araştırması yaparken hem kütüphanecilerin hem de son kullanıcıların LCSH (Library of Congress Subject Headings - ABD Kongre Kütüphanesi Konu Başlıkları) kullanma eğiliminde oldukları görülmektedir. Araştırma sonuçları, kütüphanecilerin İngilizce arama sonuçlarından daha memnun durumda olduğunu göstermektedir. Bunun nedeni, konu başlığı yapısının kütüphaneciler açısından daha tanıdık olması ve kütüphanecilerin bu tür bir aramayı daha etkili bulmaları ile açıklanabilir. Romanizasyon konusunda araştırmaya katılanların çoğunluğu, Çince, Japonca ve Korece materyallerin aranması ile ilgili endişelerini dile getirmişlerdir. Romanizasyon konusundaki tutarsızlık, Arapça ve İbranice dillerinde arama yapanlar açısından da endişe nedeni olmuştur. "Romanizasyon problemi" yaşadığını belirtenlerin oranı kütüphanecilerde \%32 olup, kullanıcılarda \%20’dir. Araştırmaya göre aradığ konusunda "İstediğimi bulamıyorum" diyen kullanıcı oranının (\%36), kütüphaneci oranından (\%21) fazla olduğu görülmektedir (El-Sherbini ve Chen, 2011, ss. 479-480).

Latin alfabesi olmayan kütüphane materyallerini bulmak için Latin harflerine dönüştürülmüş erişime sahip kataloglar tek başına yetersizdir; çünkü bu materyalleri arayanlar açısından tanıdık değillerdir. Bu noktada; bilgi teknolojisinde yaşanan gelişmelere dayanarak MARC karakter dağarcığının genişletilmesi ve Latin olmayan erişim noktalarına izin vermesi için kataloglama standardına kurallar eklenmesi önerilebilir (Agenbroad, 2006, s. 21). MARC 
formatında karakter zenginliğinin sağlanması, farklı dillerde yazılmış eserlere ilişkin bilgilerin, formatın ilgili alanlarına işlenmesi noktasında bir çözüm olabilir.

\section{Sonuç}

Çeviri, farklı kültürleri öğrenmeye, başka uygarlıklar hakkında bilgi sahibi olmaya olanak sağlayan bir olgudur. Ana dilde yazılmış bir eserin başka dillere aktarımı bu konuda yapılan çalışmaların yoğunlaşmasıyla çeşitli sistemlerin ortaya çıkmasına ve bu sistemlerin zaman içerisinde gelişmesine yardımcı olmuştur.

Çeviri yazı ve romanizasyon; dil, metin, harfler arasında aktarım yapılmasını sağlayan sistem örnekleridir. Çeviri yazıda bir dildeki tüm sesler özel karakterlerle birlikte başka bir dile aktarılırken, romanizasyonda örneğin; Kiril alfabesi gibi özel karakter ve sembollerin olduğu alfabelerdeki harflerin Latin harflerine dönüşümü söz konusudur. Diller arasındaki bu geçişler aktarım ve dönüşüm sırasında dilin anlaşılmaması, bilgi kaybı, erişim sorunu gibi problemlere yol açmaktadır.

Türkçe eski ve yeni metinler arasında alfabe farklılığından kaynaklı aktarım zorluğu, Arapça metinlerin Latin alfabesine dönüştürülmesi süreci, döneminde yaşanan siyasal gelişmelerin Türkçeye ve Türk lehçelerine olan kültürel yansımaları, Türkiye'de çeviri yazı konusunun gündeme gelmesini sağlamıştır. Günümüzde Türkçeye çevirisi yapılan eserlerin Korecede yoğunlaştığı görülmektedir.

Konuya kütüphanecilik açısından bakıldığında; özellikle Arapça ve Farsça eserlerin kataloglanmasına ilişkin problemler yaşandığını söylemek mümkündür. Dille ilgili bilgi eksikliği, harflerin dönüşümü sırasında yaşanan bilgi kaybı, harf dönüşüm şemalarının ve romanizasyon tablolarının yeterli olmaması ve kullanıcıların bilgi arama davranışı sorun oluşturabilmektedir.

Bilgi teknolojisinde yaşanan gelişmelerden yararlanılması, kullanılan formatlara farklı dillerin karakterlerinin entegre edilmesi ile karakter seçeneklerinin çoğaltılması bir çözüm olarak değerlendirilebilir.

\section{Kaynakça}

Agenbroad, J. E. (2006). Romanization is not enough. Cataloging \& Classification Quarterly, 42(2), 21-34. https://doi.org/10.1300/J104v42n02_03

Chroust, D. Z. (2001). Slavic-language material in OCLC and the search for matching records: Reconsidering an overlooked problem. Slavic \& East European Information Resources, 1(4), 4167. https://doi.org/10.1300/J167v01n04_06

Çetin Milci, E. (2015). Gregoryan muhiti Kıpçak Türkçesinin imla özellikleri. Marmara Türkiyat Araştırmaları Dergisi, II(2), 159-180.

El-Sherbini, M. ve Chen, S. (2011). An assessment of the need to provide non-roman subject access to the library online catalog. Cataloging \& Classification Quarterly, 49(6), 457-483. https://doi.org/10.1080/01639374.2011.603108

Gul, A. (2018). The declining standards of Arabic-to-roman transliteration in academic writing, editing, and publishing. Pub Res Q, 34, 1-10. https://doi.org/10.1007/s12109-018-9566-3

Husic, G. (2011). Romani language: Cataloging ramifications for a language in the process of standardization. Slavic \& East European Information Resources, 12(1), 37-51. https://doi.org/10.1080/15228886.2011.556076 
Khurshid, Z. (2002). Arabic script materials: Cataloging issues and problems. Cataloging \& Classification Quarterly, 34(4), 67-77. https://doi.org/10.1300/J104v34n04_07

Kim, S. K. (2006). Romanization in cataloging of Korean materials. Cataloging \& Classification Quarterly, 43(2), 53-76. https://doi.org/10.1300/J104v43n02_05

Korkmaz, Z. (2011). Ağız araştırmalarındaki çeviri yazı ayrılıklarının bir sisteme bağlanması gereği üzerine. Türk Dili Araştırmaları Yıllı̆̆ - Belleten, 59(1), 45-50.

Lawson, D. R. (2010). An assessment of Arabic transliteration systems. Technical Services Quarterly, 27(2), 164-177. https://doi.org/10.1080/07317130903547493

Molavi, F. (2006). Main issues in cataloging Persian language materials in North America. Cataloging \& Classification Quarterly, 43(2), 77-82. https://doi.org/10.1300/J104v43n02_06

Romanization tables. (2021, 10 Şubat). Cataloging and acquisitions: ALA-LC romanization tables. https://www.loc.gov/catdir/cpso/roman.html

Tokatlı, Ü. (2013). Çeviri - yazı üzerine bir not. Türk Dünyası Araştırmaları, 207, 201-204.

Türközü, S. G. ve Ölçer, M. (2019). Korecenin romanizasyonu ve Türkçe çevriyazısı üzerine bir çalışma. Dokuz Eylül Üniversitesi Edebiyat Fakültesi Dergisi, 6(1), 9-29.

Uzun, A. (2020). Farsça-Türkçe ve Osmanlı Türkçesi sözlüklerinde karşılaşılan çeviri yazı ve imla meseleleri üzerine bazı tespit ve değerlendirmeler. ERDEM: Insan ve Toplum Bilimleri Dergisi, 78, 241-268.

Ünver, İ. (1993). Çevriyazıda yazım birliği üzerine öneriler. Türkoloji Dergisi, 11(1), 51-89.

Wang, Y. (2000). A look into Chinese persons' names in bibliography practice. Cataloging \& Classification Quarterly, 31(1), 51-81. https://doi.org/10.1300/J104v31n01_06

Weinberg, B. (1974). Transliteration in documentation. Journal of Documentation, 30(1), 18-31.

Yavuz, E. (2018). Özbek Türkçesi-Türkiye Türkçesi arasındaki aktarım ve çeviri yazı problemleri. Atatürk Üniversitesi Edebiyat Fakültesi Dergisi, 61, 215-253. 